\title{
Research on the Mode of Urban Planning and Construction under the Concept of Green City
}

\author{
Yingwen Yu \\ School of Architecture Urban Planning Construction Engineering, Polytechnic University of Milan, Milan, Italy \\ Email: 2590044232@qq.com
}

\begin{abstract}
The history of urban planning in the world is also a history of the development of excellent planning ideas. Planning ideas have been continuously improved in urban evolution and historical baptism. Good planning has an indelible effect on the development of cities, the solution of urban problems, and the shaping of urban beauty. This article discusses the significance of planning and building a green city, analyzes the current basic conditions of urban construction, management and development, as well as existing contradictions and problems, and proposes countermeasures to solve the problems.

Keywords: green city, urban planning, urban construction
\end{abstract}

\section{Introduction}

The process of urbanization in my country is advancing rapidly, which has brought my country's urban construction into a new stage. The sustainable development of mankind is inseparable from ecological and environmental protection. Urban construction planning mainly emphasizes harmony and unity with the environment, creating a harmonious unity between man and nature, and better meeting people's diverse needs for material, cultural, and spiritual life. Thus a new model of green city planning and design is proposed. With the progress of material civilization and spiritual civilization, people have higher and higher requirements for the living environment. However, the status quo of urban planning and design in my country is generally not optimistic. Creating a new model of green city planning and construction has become the mainstream concept of modern urban design, and has gradually evolved into the core guiding ideology of urban design, reflecting the unique urban cultural connotation that promotes the rapid and sustainable development of the city.

\section{The importance of planning a green city}

Promoting green urbanization requires green city planning. With the acceleration of urbanization, urban problems have become more and more serious. Take 2011 as an example, many areas of our country have been hit by heavy rains. The urban waterlogging problem in my country has affected people's lives and travel to a certain extent. The fundamental reason is that urban construction and development are not matched, the degree of urban hardening is not enough, the green area is seriously insufficient, and the green coverage rate is low. High-standard, high-level urban planning is very important. The planning and construction of green cities is an effective way to improve people's quality of life. The comprehensive utilization of urban water resources should be incorporated into the overall urban planning, and rainwater collection and storage and reclaimed water utilization projects should be planned reasonably; the supply and demand of water resources should be balanced; attention should be paid to the protection of urban rivers, lakes, wetlands and other water systems, and the protection of groundwater resources. Combine environmental benefits and economic benefits organically; pay attention to the protection of rivers, make people's lives more hydrophilic, and form a good water ecology and living atmosphere.

\section{On the status quo and main contradictions of urban planning and construction}

At present, due to the constraints of equipment and technical capabilities, urban planning and construction in my country are relatively backward in concepts, low standards, lagging in construction, waste and serious environmental problems. Its main disadvantages are as follows. Excessive adsorption or centripetal force in the city center leads to excessive building density; excessive concentration of resources and functions, overpopulation, artificially increasing the cost of living, and bringing huge economic losses to urban life. On the contrary, the area returned to the center has not received the attention it deserves, and has gradually been marginalized; construction investment is small, and urban development is relatively backward; functional design is not matched, which can easily cause environmental degradation, 
traffic congestion, and poor ability to respond to sudden natural disasters. At the same time, there are some problems in the development of cities, such as focusing only on urban construction and neglecting management and maintenance. Many decision makers are accustomed to "top-heavy." Without scientific demonstration of urban planning, construction and development, urban expansion will form a vicious circle, making it difficult to improve the urban environment.

\section{Analysis of some problems in urban planning and construction}

\subsection{Unsystematic urban planning}

Currently, China lacks a complete urban planning system in the process of urban planning and construction. Many special plans that need to be prepared are not clearly defined. The result is often misunderstandings in the urban planning process, triggering various disputes, and making urban planning concepts fall short of the development of the times.

\subsection{Improper layout of urban construction}

Because the specific implementation of urban planning is not consistent with planning and design, it is often affected by many local interest factors, causing urban planning to be out of touch with the specific implementation of certain road sections. Among them, the construction density of the central urban area is relatively high, and some peripheral areas lack systematic planning and construction in strict accordance with a reasonable time sequence. This has caused the intensive degree of urban construction to continue to decrease, waste and restrict the long-term development of the city.

\subsection{Traffic congestion and environmental degradation}

As an important part of urban planning, the widespread application of automobile traffic has brought tremendous pressure to urban traffic to a certain extent. However, many urban planning completely ignore this point in the specific planning layout. As a result, automobile traffic, urban public transportation, bicycle traffic, etc. cannot form a branch road with a reasonable layout. Urban roads are not classified according to their nature and purpose, resulting in congestion of urban traffic and inconvenience to people's daily life.

\subsection{Neglect of the environment in urban planning}

At present, my country's urbanization and industrialization are still in their infancy. However, in the specific development process, due to the lack of planning, no indicators, and disorderly construction of industrial land, many cities have suffered serious environmental damage, and the overall pollution level is much higher than that of capitalist countries.

\section{On the countermeasures of green city planning and construction from a new perspective}

The planning and construction of the green city is a systematic project, which needs to be coordinated, broaden the horizon and improve the level. We must start from a new perspective to plan and build the green city. The whole process of urban planning, construction and management should reflect the concept of green urbanization. The promotion of green urbanization aims to conduct a systematic study of our country's urbanization system and integrate the concept of green urbanization throughout the entire urbanization plan. It is necessary to coordinate the construction of green urbanization in the planning and construction, abandon the mindset of purely urban construction, and firmly grasp the themes of green, energy saving, low carbon, and environmental protection. Change concepts and vigorously develop low-energy buildings. "Green urbanization" also includes expanding the connotation of the city and improving the quality of the city.

Building a green city is an important part of urban planning, and we must actively promote the construction of green cities. In order to make the development layout more reasonable, one third of the land in the new city is used for ecological construction, one third for industrial development, and one third for housing and public services. Don't confuse green buildings with green cities that are not just garden cities. Green city should be ecological, low-carbon, livable and environmentally friendly, and promote the development of urban consumption in a healthy, reasonable and frugal direction.

Urban environmental construction requires the persistence of the development of green cities, and the creation of garden ecological cities with a large number, good ecology, diverse plants and beautiful environment. One of the important contents of green city construction is to relieve traffic pressure. The residential area and work area should be planned as a whole, taking into account the functions of residence and work. In addition, green city's energy conservation and emission reduction issues should also focus on public buildings. Public buildings are more important than residential buildings. The energy consumption of existing public buildings is 7 times that of residential buildings. Therefore, as a green city, the renovation of original buildings should be an important task. Ideas are more important than technology, and energy-saving 
and emission-reduction technologies are far from enough. To build a green city, a green, civilized and healthy lifestyle should be promoted among citizens and all walks of life.

It is necessary to integrate green buildings with ecological cities, and take green buildings as the lead. Attach importance to the "two-wheel drive" of modern service industry and urban industry, focus on introducing and developing green industries, reduce land occupation, reduce environmental pollution, improve overall efficiency, promote urban industrial upgrading, and promote the development of ecological industrial economy. At the same time, we should base ourselves on the future and make long-term plans. First of all, long-term planning should be made, focusing on the layout of green and beautified land and urban water resources. In today's increasingly modernized transportation, to completely solve urban problems, it is necessary to gradually change from "single-center planning" to "multi-center planning".

\section{Design ideas and methods for green city planning and construction}

It is necessary to achieve an effective combination with ecological and environmental protection and take practical and effective measures to increase the construction of urban green spaces and increase the number of urban residents on the basis of not affecting the normal growth of ecological vegetation in central urban green spaces, so that the level of modern urban greening will be significantly improved.

\subsection{Innovative research on working methods of urban construction planning departments}

Urban planning management departments play a very important and effective role in specific urban planning work. To this end, national government departments should actively guide urban construction planning departments to carry out all-round institutional innovations in planning management models and management mechanisms, so as to inject new vitality into the development of urban construction planning in my country and provide a powerful force for green city construction. Guaranteed.

\subsection{Strengthen the standardized management capabilities of green city planners}

When planning and constructing a green city, we must continue to introduce professional and technical personnel to provide a strong guarantee. Existing personnel should be trained regularly, and their knowledge system should be updated in time through training to improve their quality and ability.

\section{Conclusion}

Urban planning is closely related to urban environmental protection. Not only must there be specific requirements for high standards and high quality, but also adequate and effective protection of the existing natural environment. Promote the overall stability and sustainable development of the city, and create a good living and working environment for urban residents.

\section{References}

[1] Wang Dongdong, Chen Yabin. Research on the integration mode of urban green space under the concept of park city — Based on the practice of park city planning in Tianfu New District. Zhejiang Garden. 2019; (4).

[2] Tang Hongliu, Jin Jin. Research on Urban Youth Community Design Based on the Concept of Assembly Technology — Taking the "Creative Youth Home" program as an example. Urbanism and Architecture. 2020; 017(001): $135-139$.

[3] Zhou Ye. Research on the application of green and low-carbon city development concepts in urban and rural planning. Low Carbon World. 2019; 009(008): 210-211.

[4] Wang Ruirui. Research on Urban Commercial Street Design Strategy Based on Green Low Carbon Concept. Urbanism and Architecture. 2019; 16(05): 13-14.

[5] Cao Bohu, Liu Wanfang, Gong Hang. Research on ecological city planning based on the concept of green transportation. Building Energy Efficiency. 2019; 47(09): 85-89.

[6] Zhang Yuan. A Preliminary Study on the New Type of Small Town Planning Methods in the New Era--Taking the Planning and Construction of Small Towns in Jizhou District, Tianjin as an Example. Engineering Construction. 2019; 002(007): 92-98.

[7] Liu Ziqin, Guo Shunshun. Research on the green design of super-high-rise urban complex under the background of high density - Taking Changsha Intercity Space Station as an example. Chinese and Foreign Architecture. 2020; (05): 137-139.

[8] Xiao Zhe, Yang Danli. Research on the Constraints and Development Paths in the Construction of Green City - Taking Xiaogan City, Hubei as an Example. Urbanism and Architecture. 2019; 016(013): 75-78. 
[9] Dai Fei, Wang Yunda, Chen Ming, et al. Study on the Planning and Protection of Waterfront Green Space under the Vision of "Park City": A Case Study of Hundreds-kilometers Riverbank Parks Group of the Yangtze River in Wuhan. Shanghai Urban Planning Review. 2019; 001(001): 19-26.

[10] Liu Qian, Ni Qi. Urban Riverside Greenway Landscape Planning and Design Based on Sponge City Construction: Taking the Little Dragon Riverside Greenway of Neijiang as an Example. Huazhong Architecture. 2019; (02): 95-100. 